\title{
Research of O2O User Behavior Based on Stimulus-Organism-Response Model
}

\author{
Qi Sun
}

School of Economic and Management, Beijing Jiaotong University, Beijing, 100044 China.

16120617@bjtu.edu.cn

Keywords: O2O mode; pleasure; arouse; shopping indication; SOR.

\begin{abstract}
With the development of Internet technology, nowadays more and more people choose online shopping. Based on Stimulus-Organism-Response model, according to user pleasure and arouse, this paper builds a concept model that influence customers' shopping indication. In the theory research phase, this paper comes up with four factors, which affect user behavior, that is information richness, personality, economic and visually. Those four factors work as intermediate variables. At the empirical research part, this paper presents Elemi and MeiTuanWaiMai as respondents to conduct formal researches. The reliability, validity, factor analysis and regression analysis were performed by using SPSS and EXCEL data analysis software, and the following conclusions were drawn: pleasure and arousal have significant positive effect on user's purchase intentions; information richness, personalized, economy and visually have profound effects on both pleasure and arousal, while the abundant information play a negative role in pleasure. Finally, this paper summarizes the results of the study, and make some guidance based on research findings.
\end{abstract}

\section{Introduction}

With the development of the Internet, the relatively new business model of $\mathrm{O} 2 \mathrm{O}$ has quietly entered our lives [1]. As an example, the $\mathrm{O} 2 \mathrm{O}$ model represented by Elemi and Mantuan takeout is focused on providing discounts, providing information, and services. In other ways, the offline store's message is delivered to online web users [2], making the web a frontline for offline transactions. Offline services can use the Internet to attract customers. Users can select services through the Internet and improve their consumption efficiency through online payment and settlement [3]. With the development of big data, the amount of users spending on the Internet is increasing, but the proportion of choosing $\mathrm{O} 2 \mathrm{O}$ mode as the main shopping method is not so significant. Therefore, studying the user behavior in the $\mathrm{O} 2 \mathrm{O}$ model under the SOR theoretical model also plays a guiding role for the later $\mathrm{O} 2 \mathrm{O}$ model development.

\section{Organization of the Text}

\subsection{The S-O-R Model of Consumer Behavior.}

In the 1930s, the new behaviorism gradually formed the S-O-R model. S represents the stimulus that causes the individual to respond, $\mathrm{O}$ represents the organism or the body of the reaction, and $\mathrm{R}$ represents the response caused by the stimulus. Belk [4] applied the SOR model to marketing and proposed a stimulus-body-response model [5, 6]. In addition, Biter [7] proposed a consumer behavior model based on the psychology SOR model. He believes that consumers have cognitive, emotional, and physical responses to external stimuli, and these reactions affect consumer behavior.

\subsection{The SOR Theoretical Model Study.}

The SOR model can link external stimuli with perception and response better in the body. When Mehrabianetal [8] studied consumer behaviors, the SOR model was very effective in studying external factors and consumer intrinsic behavioral responses. Based on the model, using the quality of the website to study consumer sentiment to study the user behavior in the $\mathrm{O} 2 \mathrm{O}$ model under the SOR theory model. 
In user behavior, emotions as internal factors influencing consumer behavior are often used to study purchasing motivation. Emotions are closely related to needs, motivation, and personality. The unmet need creates motivation that motivate certain emotional components. Mehrabian and Russell [9] proposed a theoretical model based on SOR. Zhang Hulu 2011[10] mentioned the two latitudes of pleasure, "pleasure and awakening," and the model was later widely used to explore the relationship between external stimuli, consumer perception, and behavioral intent under online shopping. Based on the above model, based on the characteristics of $\mathrm{O} 2 \mathrm{O}$ website and the analysis of user behavior, this paper constructs the SOR theoretical model of the influence of $\mathrm{O} 2 \mathrm{O}$ website on the user's purchase intention.

\section{Research Hypothesis of O2O User Behavior and Model Establishment}

\subsection{The Influence of Four Factors on User's Pleasure and Arousal under the SOR Theory.}

The timeliness, readability and richness of website information have a very important influence on the purchase intention of online users. In this case, the information asymmetry faced by users is also greatly improved. Many users are faced with the information redundancy when they consume on the O2O platform. So we make the following assumptions:

$\mathrm{H} 1 \mathrm{a}$ : The richness of information on the $\mathrm{O} 2 \mathrm{O}$ website under the SOR model will improve the user's pleasure. $\mathrm{H} 1 \mathrm{~b}$ : The richness of $\mathrm{O} 2 \mathrm{O}$ website information under the SOR model will increase the level of awakening of users

Personalized marketing tools can make users active in Internet sales. Using the SOR theoretical model to analyze the massive data, the user's preferences and habits were recorded using the data mining method to implement the recommendation system. Users can find the most desired products and services in the shortest time through personalized features. So we make the following assumptions:

$\mathrm{H} 2 \mathrm{a}$ : The personalized service of $\mathrm{O} 2 \mathrm{O}$ website information under the SOR theory model will improve the user's pleasure perception. $\mathrm{H} 2 \mathrm{~b}$ : The personalized service of $\mathrm{O} 2 \mathrm{O}$ website information under the SOR theory model will increase the arousal level of users

The biggest advantage of the $\mathrm{O} 2 \mathrm{O}$ platform is its price advantage. Under the SOR theoretical model platform, more price information than traditional platforms can be collected to compare prices, select the products that are most suitable for consumer, and increase the impulse of their purchase. So we make the following assumptions:

H3a: The economy of $\mathrm{O} 2 \mathrm{O}$ website products under the SOR theory model will increase users' pleasure perception. H3b: Economics of O2O Website Products under SOR Theory Will Increase Users' Arousal

The aesthetic design of the $\mathrm{O} 2 \mathrm{O}$ website platform is directly related to the number of users. When the design of the website meets the requirements of the users, it is easier for the consumers to have a sense of pleasure, and thus increase the success rate of the transaction [11]. So we make the following assumptions:

H4a: The aesthetics of the $\mathrm{O} 2 \mathrm{O}$ website under the SOR model will increase users' pleasure. H4b: The aesthetics of the $\mathrm{O} 2 \mathrm{O}$ website under the SOR model will increase the level of arousal of users

\subsection{Establishment of the Research Model.}

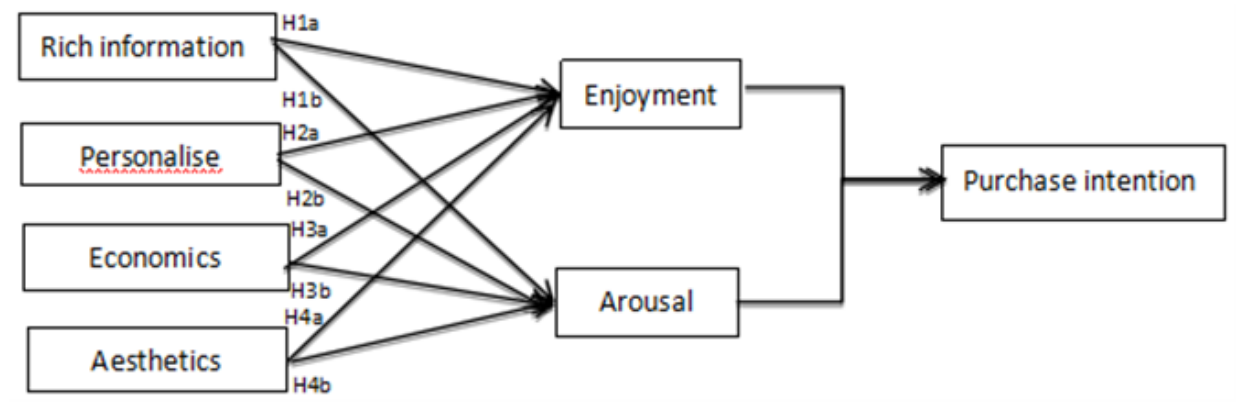

Fig 1. Research Model 


\section{Research Design of O2O User Behavior under SOR Theory}

\subsection{Data Collection.}

In this study, 300 questionnaires were distributed on the online platform questionnaire, and 252 valid questionnaires were retrieved. The questionnaires were $84 \%$ efficient. The first part of the questionnaire was basic personal information, as shown in Table 1. The second part included information richness, personalization. The economics, aesthetics on the factors of enjoyment and awakening in the SOR model, and the effect of pleasure and arousal on the purchase intention of consumers. Questionnaire questions were measured using a 7-point Likert scale. As shown in table 2.

Table 1. Basic Information Survey

\begin{tabular}{|c|c|}
\hline Your gender & A male $B$ female \\
\hline Your age group & $\begin{array}{c}\text { A } 18 \text { or less } \text { B } 18-25 \text { C } 26-30 \text { D } 31-40 \\
\text { E } 41-50 \text { F } 51-60 \text { G } 60 \text { or more }\end{array}$ \\
\hline Your current occupation & $\begin{array}{l}\text { A Full-time student B has joined the job C } \\
\text { Freelance D Other }\end{array}$ \\
\hline Your monthly income & $\begin{array}{c}\text { A 3000RMB or less B 3000-5999 C 6000-8999 } \\
\text { D } 9000 \text { or more }\end{array}$ \\
\hline $\begin{array}{c}\text { Do you use some O2O platforms (e.g. Crip, Elemi and } \\
\text { Mantuan takeout etc.?) }\end{array}$ & A Yes \\
\hline $\begin{array}{c}\text { How often do you use the O2O platform (e.g. Crip, } \\
\text { Hungry, and U.S. Takeout etc.?) }\end{array}$ & A Daily B Weekly C Monthly D Hardly used \\
\hline
\end{tabular}

Table 2. Research Variables

\begin{tabular}{c|c|c}
\hline Variable & Title & Question \\
\hline \multirow{2}{*}{$\begin{array}{c}\text { Rich } \\
\text { information }\end{array}$} & 1 & Compared with other e-commerce models, shopping information on the O2O platform is \\
very rich.
\end{tabular}

\subsection{SPSS Multiple Regression Analysis.}

\subsubsection{Principles of Multiple Regression Analysis.}

Let the linear regression equation of n-ray for $\mathrm{y}$ to $\mathrm{x} 1, \mathrm{x} 2 \ldots$ and be:

$$
\hat{y}=b_{0}+b_{1} x_{1}+b_{2} x_{2}+\ldots+b_{n} x_{n}
$$

$b_{0}, b_{1}, b_{2}, \ldots, b_{n}$ Are regression coefficients, should minimize the sum of the squared deviations of the regression estimates from the actual observations.

Let $Q=\sum_{j=1}^{m}\left(y_{j}-\hat{y}_{j}\right)^{2}=\sum_{j=1}^{m}\left(y_{j}-b_{0}-b_{1} x_{1 j}-b_{2} x_{2 j}-\ldots-b_{n} x_{n j}\right)^{2} \mathrm{Q}$ is an $\mathrm{n}+1$-ary function about

$b_{0} 、 b_{1}, b_{2}, \ldots, b_{n} \quad$. According to the method of differential calculus for multivariate functions, to minimize $\mathrm{Q}$, we should have: 


$$
\left(\begin{array}{l}
\frac{\partial Q}{\partial b_{0}}=2 \sum_{j=1}^{m}\left(b_{0}+b_{1} x_{1 j}+b_{2} x_{2 j}+b_{3} x_{3 j}+\ldots-y_{j}\right)=0 \\
\frac{\partial Q}{\partial b_{i}}=2 \sum_{j=1}^{m}\left(b_{0}+b_{1} x_{1 j}+b_{2} x_{2 j}+b_{3} x_{3 j}+\ldots-y_{j}\right)\left(x_{i j}\right)=0
\end{array}\right.
$$

After finishing, the regression coefficients can be solved, then we get the n-ray regression equation:

$$
\bar{y}=b_{0}^{\prime}+b_{1}^{\prime} x_{1}+b_{2}^{\prime} x_{2}+\ldots+b_{n}^{\prime} x_{n}
$$

\subsubsection{SPSS Regression Model Analysis Test.}

In this paper, the four variables of information richness, personalization, economics, and visually are used as independent variables, and pleasure and arousal are used as dependent variables. Two regression equations are established as follows:

$$
\begin{aligned}
& y_{1}=b_{0}+b_{1} x_{1}+b_{2} x_{2}+b_{3} x_{3}+b_{4} x_{4} \\
& y_{2}=\alpha_{0}+\alpha_{1} x_{1}+\alpha_{2} x_{2}+\alpha_{3} x_{3}+\alpha_{4} x_{4}
\end{aligned}
$$

a. Goodness of fit test

For the regression equations (4) and (5), both the $\mathrm{R}$ value and the $\mathrm{R}$ square value are close to 1 , so the goodness of fit is good and the model is established. As shown in Table 3.

Table 3. Model Summary b

\begin{tabular}{c|c|c|c|c}
\hline Model & $\mathrm{R}$ & $\mathrm{R}$ Square & Adjusted R-square & Estimated Error \\
\hline 1 & $.728 \mathrm{a}$ & .820 & .822 & .24530 \\
\hline 2 & $.755 \mathrm{a}$ & .859 & .863 & .19103 \\
\hline
\end{tabular}

b. Significant $F$ test

As shown in Table 4, the Sig values of the regression equation are all less than 0.05 , indicating that

\begin{tabular}{|c|c|c|c|c|c|c|}
\hline \multicolumn{2}{|r|}{ Model } & Square sum & Degree of freedom & Mean square & $\mathrm{F}$ & Significance \\
\hline \multirow{3}{*}{1} & Return & 198.449 & 4 & 49.612 & 69.434 & .0000 \\
\hline & Residuals & 176.488 & 247 & .715 & & \\
\hline & Total & 374.937 & 251 & & & \\
\hline \multirow{3}{*}{2} & Return & 204.440 & 4 & 51.110 & 81.680 & .0000 \\
\hline & Residuals & 154.556 & 247 & .626 & & \\
\hline & Total & 358.996 & 251 & & & \\
\hline
\end{tabular}
there is a true linear relationship between the dependent variable and the independent variable, which can pass the significance test.

Table 4. Significance F Test

\section{c. Significant $t$ test}

From Table 5, it can be seen that sig is less than 0.05 between 0.0032 and 0.000 . It can be seen that the regression coefficient test result is significant, and the correlation coefficient is between 0.834 and 0.998 , which is close to 1, indicating that the test data exists between Strong correlations. 
Table 5. Coefficient ${ }^{\mathrm{a}}$

\begin{tabular}{|c|c|c|c|c|c|c|c|}
\hline & \multirow{2}{*}{ Model } & \multicolumn{2}{|c|}{ Unnormalized coefficient } & \multicolumn{2}{|c|}{ Normalized coefficien } & \multirow{2}{*}{$\mathrm{t}$} & \multirow{2}{*}{ Significant } \\
\hline & & $\mathrm{B}$ & Standard error & & & & \\
\hline \multirow{5}{*}{1} & (constant) & .653 & .303 & & & 2.159 & .0032 \\
\hline & Rich information & -.113 & .049 & & & -2.326 & .0021 \\
\hline & \begin{tabular}{|l|} 
Personalise \\
\end{tabular} & .130 & .058 & & & 2.232 & .0027 \\
\hline & Economics & .314 & .063 & & & 4.993 & .0000 \\
\hline & aesthetics & .334 & .049 & & & 6.804 & .0000 \\
\hline \multirow{5}{*}{2} & \multicolumn{2}{|c|}{ (constant) } & .643 & .275 & & 2.341 & .0020 \\
\hline & \multicolumn{2}{|c|}{ Personalise } & .173 & .054 & .187 & 3.199 & .0002 \\
\hline & \multicolumn{2}{|c|}{ Economics } & .322 & .059 & .314 & 5.452 & .0000 \\
\hline & \multicolumn{2}{|c|}{ aesthetics } & .305 & .047 & .330 & 6.544 & .0000 \\
\hline & \multicolumn{2}{|c|}{ Rich information } & .090 & .046 & .120 & 2.326 & .0021 \\
\hline
\end{tabular}

d. Regression equation

Based on the analysis of the above regression results, a multiple linear regression model may be considered, and its estimation equation is:

$$
\begin{aligned}
& y_{1}=0.653-0.113 x_{1}+0.130 x_{2}+0.314 x_{3}+0.334 x_{4} \\
& y_{2}=0.643+0.173 x_{1}+0.322 x_{2}+0.305 x_{3}+0.090 x_{4}
\end{aligned}
$$

\subsubsection{SPSS Regression Model Analysis Test.}

Table 6. Analysis of Regression Results

\begin{tabular}{c|c|c|c|c}
\hline Hypothesis & Study Hypothesis & Factor & T Value & Verification Results \\
\hline $\mathrm{H} 1 \mathrm{a}$ & Rich information->Enjoyment & -0.113 & -2.326 & Established \\
\hline $\mathrm{H} 1 \mathrm{~b}$ & Rich information->Arousal & 0.173 & 3.199 & Established \\
\hline $\mathrm{H} 2 \mathrm{a}$ & Personalize->Enjoyment & 0.130 & 2.232 & Established \\
\hline $\mathrm{H} 2 \mathrm{~b}$ & Personalize->Arousal & 0.322 & 5.452 & Established \\
\hline $\mathrm{H} 3 \mathrm{a}$ & Economics->Enjoyment & 0.314 & 4.993 & Established \\
\hline $\mathrm{H} 3 \mathrm{~b}$ & Economics->Arousal & 0.305 & 6.544 & Established \\
\hline $\mathrm{H} 4 \mathrm{a}$ & Aesthetics->Enjoyment & 0.334 & 6.804 & Established \\
\hline $\mathrm{H} 4 \mathrm{~b}$ & Aesthetics->Arousal & 0.0 .90 & 2.326 & Established \\
\hline
\end{tabular}

Through the regression equation, it can be seen that information richness has a negative impact on enjoyment, but it has a positive effect on arousal; personalize, economics, and aesthetics all have a positive effect on enjoyment and arousal.

\section{Summary}

Rich information content has a negative effect on the consumer's sense of pleasure, but it awakens consumers' desire for partial purchase. It is hoped that the $\mathrm{O} 2 \mathrm{O}$ platform will disseminate richer information content to customers who can process a large amount of information in a short time, and deliver the information they really need to target people who receive a large amount of limited information. In terms of personalization, we can use the SOR theory to reasonably collect a wide range of consumer information for each user, perform corresponding association and cluster analysis, provide personalized services, and increase customer purchase intentions. Economics have a significant positive effect on the pleasure and awakening of two intermediate variables. As 020 businesses, they should actively launch affordable packages and occupy more market share. Aesthetics has a significant effect on both pleasure and awakening. It can be seen that consumers are more rational in their current consumption in China, and they are more concerned with the evaluation and experience of other users on the $\mathrm{O} 2 \mathrm{O}$ platform. 


\section{References}

[1]. Mahongchun. the Analysis of Application Status of O2O E-commerce Model in China [J]. Technology Vision. Vol. 42 (2008), p. 15-19.

[2]. Huangyuanpu. Damping and Elemi grab the O2O market [J]. Global business classic. Vol. 7 (2014), p. 211-216.

[3]. Wangi. Research on the development strategy of small and medium enterprises mobile commerce based on O2O model [J]. China's trade. Vol. 23 (2012), p. 119-120.

[4]. Belk, Russell Situational Variables and Consumer Behaviour" [J].Jamal of Consumer Research. Vol. 2 (1995), p. 119-120.

[5]. Xuguohu, Sunning, Xu fang. Research on data mining of online and offline e-commerce users based on the SOR theory model [J]. Journal of hangman Nationalities University. Vol. 4 (2013), p. 101-102.

[6]. Fanning, Banyan, Huangliujia. Research on the effect of social networking sites based on stimulus-body-response theory [J]. Shanghai management science. Vol. 36(2014), p. 113-115.

[7]. Biter, Mary. The Impact of Physical Surroundings on Customers and Employees [J]. Journal of Marketing. Vol. 56(1992), p. 57-71.

[8]. Mehrabianetal. Perceived usefulness, perceived ease of use and user acceptance of information technology [J]. Information Systems Research. Vol. 9(1989), p. 319-340.

[9]. Mehrabian, Russell. Applying the technology acceptance model and flow theory to online consumer behaviour [J]. MIS Quarterly. Vol. 13(2002), p. 205-223.

[10]. Zhangyulu. Application of S-O-R model in the study of apparel network consumption behaviour [J]. International textile guide. Vol. 7(2011), p. 21-25.

[11]. Hengyang, Weishoubo. Empirical research on the influence of virtual atmosphere on online consumer impulse buying [J]. International textile guide. Vol. 11(2013), p. 45-52. 